July 2009

\title{
Plating for Anterior Cervical Fusion
}

\author{
Ciro Randazzo MD, MPH
}

Follow this and additional works at: https://jdc.jefferson.edu/jhnj

\section{Let us know how access to this document benefits you}

\section{Recommended Citation}

Randazzo, Ciro MD, MPH (2009) "Plating for Anterior Cervical Fusion," JHN Journal: Vol. 4 : Iss. 3 , Article 5.

DOI: https://doi.org/10.29046/JHNJ.004.3.005

Available at: https://jdc.jefferson.edu/jhnj/vol4/iss3/5

This Article is brought to you for free and open access by the Jefferson Digital Commons. The Jefferson Digital Commons is a service of Thomas Jefferson University's Center for Teaching and Learning (CTL). The Commons is a showcase for Jefferson books and journals, peer-reviewed scholarly publications, unique historical collections from the University archives, and teaching tools. The Jefferson Digital Commons allows researchers and interested readers anywhere in the world to learn about and keep up to date with Jefferson scholarship. This article has been accepted for inclusion in JHN Journal by an authorized administrator of the Jefferson Digital Commons. For more information, please contact: JeffersonDigitalCommons@jefferson.edu. 


\section{Plating for Anterior Cervical Fusion}

\author{
Ciro G. Randazzo, MD \\ Department of Neurological Surgery, Thomas Jefferson University, Philadelphia, PA
}

The use of anterior cervical plating to supplement anterior cervical decompression and fusion still remains controversial. The rate of fusion for single-level ACDF remains above $90 \%$ in most reports. There is no professional organization or group that has established any guideline for plate fixation in single level anterior cervical decompression. The cost and possible increased operative time and morbidity are factors that should be considered in foregoing anterior plating. The following recommendations are based on the review of the most current literature for anterior cervical decompression and fusion:

- In single level anterior cervical decompression and fusion where autologous iliac crest bone graft is used, anterior plating is not recommended.

- In single level anterior cervical decompression and fusion where allograft iliac crest bone graft is used, anterior plating may increase the rate of fusion. However, the additional cost of plating is now accompanied by the additional cost of allograft.

- In single level anterior cervical decompression and fusion performed for correction of a traumatic injury, autograft and plating are both recommended.

- In single level anterior cervical decompression and fusion performed on smokers, whether allograft or autograft is used, plating is recommended. Although the cost of plating is significant, any patient that is at high risk of nonunion due to risk factors such as smoking should be plated because the morbidity and cost of repeat multilevel surgery to correct pseudoarthrosis is higher.

A search of Medline, the Cochrane database, the National Guidelines Clearinghouse, the Congress of Neurological Surgeons, the American Association of Neurological Surgeons, the American Association of Orthopedic Surgeons, North American Spine Society and AOSpine was carried out using subject headings and keywords which included ACDF, ACD, anterior cervical decompression and fusion, cervical spine surgery, plating and cervical surgery. No clinical guidelines for or against the use of anterior cervical plating system in single level decompression and fusion were found.

As a result of the absence of practice parameters, recent references that provide practice recommendations were reviewed. These references include:

1. Kaiser MG, Haid RW, Subach BR, Barnes B, Rodts GE. Anterior cervical plating enhances arthrodesis after discectomy and fusion with cortical allograft. Neurosurgery, 2002 Feb: 50(2): 229-28

2. Epstein NE. Anterior cervical discectomy and fusion without plate instrumentation in 178 patients. J Spinal Disord. 2000 Feb; 13(1): 1-8

3. Bolesta MJ, Rechtine GR 2nd, Chrin AM. One and two-level anterior cervical discectomy and fusion: the effect of plate fixation. Spine J. 2002 May-Jun; 2(3); 197-203

4. Samartzis D, Shen FH, Lyon C, Phillips M, Goldberg EJ, An HS. Does rigid instrumentation increase the fusion rate in one-level anterior cervical discectomy and fusion? Spine J. 2004 NovDec; 4(6): 636-643

Practice recommendations were formulated from the results of these studies.

Kaiser MG, Haid RW, Subach BR, Barnes B, Rodts GE. Anterior cervical plating enhances arthrodesis after discectomy and fusion with cortical allograft. Neurosurgery, 2002 Feb: 50(2): 229-28

A retrospective review of 251 patients who underwent one or two level ACDF with cortical allograft and plate stabilization. Follow-up for fusion ranged between 9 months to 3.6 years. Successful fusion was defined as the absence of lucency around the graft, evidence of bridging bone between the endplate and the graft and the absence of movement on dynamic imaging.
The control group was 289 patients who had undergone ACDF without plating as described in a previously published report by the same authors.

These authors describe a $96 \%$ fusion rate for one-level ACDF with anterior plate fixation. This was a statistically significant increase in the fusion rate from the control group. They also report no infectious, neurological or graft-related complications among the patients treated with plating. They also report a statistically significant decrease in graft-related complications with the application of plates.

The authors conclude that plating ACDFs with allograft enhances arthrodesis with negligible complication rates and therefore is justified.

This is a strong study because of the large number of patients. However, the authors do not discuss the significant increase in cost for an ACDF with the use of both allograft and plating. Also, the authors use a historical cohort group as their control group. It is unknown if the two groups are comparable from baseline characteristics.

Epstein NE. Anterior cervical discectomy and fusion without plate instrumentation in $\mathbf{1 7 8}$ patients. J Spinal Disord. 2000 Feb; 13(1): 1-8 Prospective series of 178 patients undergoing one (78 patients) to four-level anterior cervical discectomy and fusion using autograft iliac crest bone graft without plating. Average follow up was 75 months. Successful fusion was defined by dynamic radiographs, which showed fusion or pseudarthrosis without motion. CT was also used to evaluate for bony fusion. Dynamic radiographs and CT showed fusion or pseudoarthrosis without motion in $99 \%$ of patients undergoing one-level ACDF. The authors conclude that the addition of plates in single-level ACDF did not appear to improve the fusion rate significantly.

This study makes a strong case for autograft ICBG without plating. The authors included a moderate number of patients with long follow-up. However the study is limited by the lack of a control group. Also, the series is limited to a single surgeon. The study also does not address possible costs and postoperative complications and ill effects associated with 


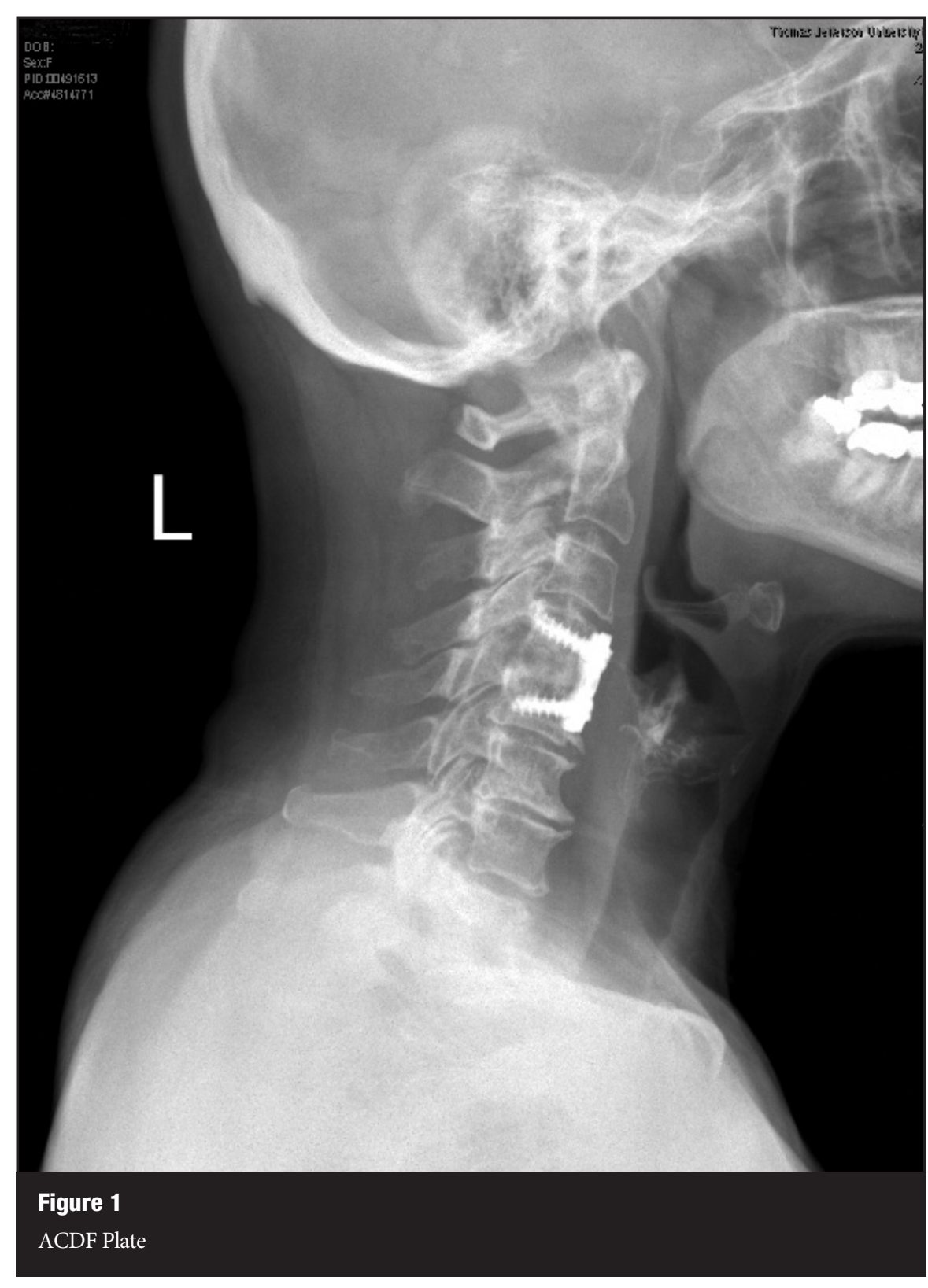

autograft harvesting. Hip pain due to harvest often hampers postoperative recovery more than any other factor.

Bolesta MJ, Rechtine GR 2nd, Chrin AM. One and two-level anterior cervical discectomy and fusion: the effect of plate fixation. Spine J. 2002 May-Jun; 2(3); 197-203

A prospective study of 40 patients undergoing one-level (20 patients) and two-level (20 patients) ACDF with autograft iliac crest bone graft. Radiographic union, postoperative pain relief and neurologic recovery were evaluated at an average follow-up of 51 months. Fusion was seen in 11/16 (69\%) of unplated fusions and $2 / 4(50 \%)$ of plated fusions. The authors conclude that plates should be used to improve multi-level fusions.

This study is limited because it is a very small study with short follow-up. Also, the rate of fusion for single-level procedures is very low compared to what has been reported throughout the literature, usually upwards of $90 \%$.

\section{Samartzis D, Shen FH, Lyon C, Phillips}

M, Goldberg EJ, An HS. Does rigid instrumentation increase the fusion rate in one-level anterior cervical discectomy and fusion? Spine J. 2004 Nov-Dec; 4(6): 636-643

A review of 69 patients undergoing one-level ACDF with autograft with or without plate fixation. Patients had a mean follow up of 14 months and were evaluated for radiographic evidence of fusion and clinical outcome. Thirty-eight patients underwent ACDF without plating and 31 patients underwent ACDF with plating.

The results showed that $100 \%$ of nonplated patients achieved a solid fusion vs. $90.3 \%$ of plated patients. There was no statistically significant difference noted between the nonplated and plated patients fusion rate. No significant intraoperative or postoperative complications occurred in either group. There was no statistical significance noted in clinical outcome between fused and nonfused patients and the use of plating.

The authors conclude that solid bone fusion can be adequately achieved with or without plating. They recommend that plating be reserved for those unwilling or unable to wear a hard orthosis postoperatively for an extended period of time or for those patients who seek a quicker return to normal activities.

This study has a moderate sample size with well-matched controls. However, the follow-up is short. Also, the authors conclude that plating should be used when a hard orthosis cannot be used or when a more rapid return to normal activities is desired. The authors' data does not support this final statement. 